\title{
Influence of digestion procedures on the determination of rare earth elements in peat and plant samples by USN-ICP-MS
}

\author{
Michael Krachler, ${ }^{* a}$ Carola Mohl, ${ }^{b}$ Hendrik Emons $^{b}$ and William Shotyk ${ }^{a}$ \\ ${ }^{a}$ Institute of Environmental Geochemistry, University of Heidelberg, Heidelberg, Germany \\ ${ }^{b}$ Institute of Phytospheric Research, Research Centre Juelich, Juelich, Germany. \\ E-mail: krachler@ugc.uni-heidelberg.de; Fax: +4962 215449 56; Tel: +49 6221544848
}

www.rsc.org/jaas

\author{
Received 22nd January 2002, Accepted 10th April 2002 \\ First published as an Advance Article on the web 14th May 2002
}

Analytical procedures for the determination of rare earth elements (REE) in $250 \mathrm{mg}$ aliquots of difficult-todigest peat and plant matrices by ICP-MS were developed. Three different pressurised digestion approaches were tested for this purpose, namely (i) closed vessel acid digestion on a hot-plate at $180{ }^{\circ} \mathrm{C}$, (ii) digestion in a microwave high pressure autoclave at a temperature of $240{ }^{\circ} \mathrm{C}$ and (iii) high pressure ashing (HPA) at a temperature of $320{ }^{\circ} \mathrm{C}$. Acid mixtures for digestion contained concentrated nitric acid $(3-5 \mathrm{ml})$ alone or additions of hydrofluoric acid $(\mathrm{HF})$ or tetrafluoroboric acid $\left(\mathrm{HBF}_{4}\right)$ at volumes of $0.05-1.0 \mathrm{ml}$. The selection of appropriate volumes of $\mathrm{HF}$ or $\mathrm{HBF}_{4}$ was identified as a critical step in obtaining accurate results. For several reasons, $\mathrm{HBF}_{4}$ is preferred in comparison with the normally used addition of $\mathrm{HF}$ for the destruction of siliceous matter in the samples investigated. The optimum acid mixture consisted of $3 \mathrm{ml}$ of $\mathrm{HNO}_{3}$ and $0.1 \mathrm{ml}$ of $\mathrm{HBF}_{4}$. High sample throughput (40 samples simultaneously in about $2 \mathrm{~h}$ ) favours the microwave autoclave over the other two digestion systems. An ultrasonic nebuliser (USN) with membrane desolvation used for sample introduction reduced the spectral interferences originating from oxide formation of lighter REE and Ba to a negligible extent. Internal standardisation with $\mathrm{Rh}$ and $\mathrm{Re}$ proved to be essential for obtaining correct results. In this way, all REE could be reliably quantified by USN-ICP-MS without applying any mathematical correction equations. The accuracy of the optimised procedures was assessed by the determination of REE in digests of the certified reference material GBW 07602 Bush Branches and Leaves and of the candidate reference material CRM 670 Aquatic Plant. The developed analytical procedures were applied to the determination of REE in two different peat matrices. Results for these peat samples obtained by USN-ICP-MS showed good agreement with INAA values. Strong fractionation of REE caused by the addition of $\mathrm{HF}$ or $\mathrm{HBF}_{4}$ in excess, known as lanthanide contraction, could be experimentally established, except for europium, which revealed a different behaviour.

\section{Introduction}

In recent years, the quantitative determination of rare earth elements (REE) has gained in importance..$^{1-13}$ Besides a variety of industrial applications, REE are of increasing relevance to geological, geochemical and environmental studies. Among the most commonly utilised approaches for REE determinations are neutron activation analysis (NAA), X-ray fluorescence (XRF) spectrometry, isotope dilution mass spectrometry, ICP-AES and ICP-MS. ${ }^{1-13}$

ICP-MS is nowadays by far the most frequently employed analytical technique to quantify REE from $\mu \mathrm{g} \mathrm{g}^{-1}$ levels in steel ${ }^{10}$ to ultratrace levels in aqueous samples. ${ }^{11}$ However, two latent problems may hamper the reliable quantification of REE by ICP-MS, especially in geochemical and environmental matrices: (i) the dissolution of siliceous material; and (ii) the occurrence of spectral interferences in the mass spectrum.

Solid material is commonly dissolved by heating with acids in either open or closed vessels. Disadvantages of open vessel digestion systems include the greater risk of loss of volatile elements. Therefore, closed vessel digestion systems are preferred in cases where subsequent trace element analyses are planned. ${ }^{14,15}$ Digestion of silicate containing material is normally achieved by adding hydrofluoric acid to the digestion mixture which attacks silicates and quartz particles and liberates silicon as the volatile $\mathrm{SiF}_{4}$. The amount of $\mathrm{HF}$ needed in the digestion will depend on the mass of silicates present in the sample. ${ }^{14}$ Especially critical in this respect is "excess" of HF that is not consumed during digestion, i.e. not used for the destruction of silicates. Many elements such as $\mathrm{Ca}$ and REE form insoluble fluorides that will precipitate in digestion solutions containing excess of fluoride, resulting in too low recoveries of these elements. ${ }^{16}$ Therefore, several researchers have proposed the addition of a saturated solution of boric acid $\left(\mathrm{H}_{3} \mathrm{BO}_{3}\right)$ to the resulting solution after digestion to overcome this problem. ${ }^{2,10}$ Precipitated fluorides will thus be redissolved and excess of $\mathrm{HF}$ will be complexed as $\mathrm{BF}_{4}{ }^{-}$. This addition of $\mathrm{H}_{3} \mathrm{BO}_{3}$, however, has two severe drawbacks. First, a heavy matrix load is introduced into the ICP-MS. Second, and perhaps more important, $\mathrm{H}_{3} \mathrm{BO}_{3}$ contains relevant amounts of elemental impurities which will lead to elevated detection limits for the elements investigated. ${ }^{2}$

In addition to the dissolution of the REE themselves, the occurrence of severe spectral and non-spectral interferences may hamper their reliable determination by ICPMS. Separation of REE from the matrix by cation exchange chromatography, ${ }^{4}$ solvent extraction ${ }^{6}$ or by using a flow injection on-line filterless precipitation-dissolution system ${ }^{9}$ or a chelating resin ${ }^{5}$ efficiently helps to reduce those interferences. These procedures can also be used to preconcentrate REE, which leads to further improvements in method detection limits. However, it is desirable to develop a more straightforward approach which would be both faster, as well as less prone to analyte loss and/or contamination. Normally, pneumatic nebulisation of the digestion solution requires extensive mathematical correction of ICP-MS signals if the ratio of light REE to heavy REE is high to take into account the oxide formation of potential interfering elements on REE. ${ }^{1}$ 
Spectral overlaps of polyatomic ions $\left(\mathrm{MO}^{+}, \mathrm{MOH}^{+}\right.$, etc. $)$of light REE on heavy REE are of particular concern for ICPquadrupole mass spectrometers. Additionally, matrix-induced polyatomic ions of $\mathrm{BaO}^{+}$and $\mathrm{BaOH}^{+}$on REE from $m / z 146$ (Nd) through to $\mathrm{m} / \mathrm{z} 155(\mathrm{Gd})$, including ${ }^{151} \mathrm{Eu}$ and ${ }^{153} \mathrm{Eu}$, are known to plague the reliable quantification of these elements. ${ }^{4}$ The determination of the mono-isotopic elements ${ }^{45} \mathrm{Sc}$ and ${ }^{89} \mathrm{Y}$ by ICP-MS has been reported to be severely hampered by the occurrence of many spectral interferences. ${ }^{1,2}$ Several spectral interferences can be separated from the REE signals by sectorfield instruments using high resolution $(m / \Delta m \sim 9000)$, at the cost of a reduced ion transmission rate, however. ${ }^{1}$

In an ultrasonic nebuliser (USN) the aerosol that is generated passes through a desolvation unit. Thus the aerosol is dried and this directly reduces the abundance of $\mathrm{MO}^{+}$and $\mathrm{MOH}^{+}$species which subsequently enter the plasma. Using this approach, REE could be successfully determined in fresh waters by USN-ICP-MS at levels as low as $0.01 \mathrm{ng} 1^{-1} \cdot{ }^{11} \mathrm{~A}$ USN consisting of an extra membrane desolvation unit also helps to lower the concentration of interfering polyatomic ions in the aspirated solution. Solvents $\left(\mathrm{H}_{2} \mathrm{O}, \mathrm{HNO}_{3}\right.$, etc. $)$ and dissolved gases are transferred into the gaseous phase by evaporation and thereby separated from the dried aerosol by diffusion through the membrane. Similarly, a microconcentric nebuliser (MCN) with membrane desolvation coupled to an ICP-MS has been successfully employed to determine REE in various matrices, including geochemical samples such as sediments and soil. ${ }^{2}$ While an MCN could reduce oxide interferences until they became negligible, the high salt load led to frequent blockage of the membrane. ${ }^{2}$ As the aerosol generation of high efficiency nebulisers such as the MCN or USN is strongly dependent on the concentration of total dissolved solids in the samples, suppression of the analyte signal varies from sample to sample as a function of their chemical composition. ${ }^{11}$ Therefore, the choice of an appropriate internal standard is of fundamental importance to correct for these signal instabilities.

The present study was undertaken to develop a simple, robust and reliable analytical procedure for the quantification of REE in peat samples. Tetrafluoroboric acid $\left(\mathrm{HBF}_{4}\right)$ was evaluated for the replacement of $\mathrm{HF}$ and $\mathrm{H}_{3} \mathrm{BO}_{3}$ in digestion solutions with the hope of attacking the silicates while preventing the loss of analytes via precipitation as metal fluorides. For ICP-MS measurements, a USN with membrane desolvation was employed with the aim of reducing the amount and number of potentially interfering polyatomic species. The new methods will be applied to the determination of REE in ancient peat bogs.

\section{Experimental}

\section{Instrumentation}

Powdered samples were dissolved in closed pressurised digestion vessels $(30 \mathrm{ml})$ made from PTFE fixed in stainlesssteel jackets (home-made) on a hot-plate. Additionally, two autoclaves (HPA, high pressure asher, Paar, Graz, Austria, and an ultraCLAVE II, MLS GmbH, Leutkirch, Germany) based on different heating principles operating at elevated pressure were employed for sample digestion.

ICP-MS measurements were carried out with an Elan 5000 (PerkinElmer SCIEX) equipped with an autosampler (AS 90, PerkinElmer) and an ultrasonic nebuliser (USN) with membrane desolvation (U-6000 $\mathrm{AT}^{+}$, Cetac Technologies, Omaha, NE, USA). Gas flows and the position of the torch were adjusted to obtain the lowest possible oxide formation rates for $\mathrm{Ce}$ and $\mathrm{Ba}$ and the maximum count rates for ${ }^{103} \mathrm{Rh}$. Typical ratios obtained for $\mathrm{CeO} / \mathrm{Ce}$ and $\mathrm{BaO} / \mathrm{Ba}$ were around 0.07 and $0.02 \%$, respectively. Under the optimised operating conditions,
Table 1 Operating conditions for the quadrupole ICP-MS

\begin{tabular}{|c|c|}
\hline Instrument: & $\begin{array}{l}\text { Elan } 5000 \text { (PerkinElmer, Norwalk, } \\
\text { CT, USA) }\end{array}$ \\
\hline Forward power & $1200 \mathrm{~W}$ \\
\hline Cones & Nickel \\
\hline Plasma gas & $15.01 \mathrm{~min}^{-1}$ \\
\hline Nebulizer gas & $\begin{array}{l}\sim 1.01 \mathrm{~min}^{-1} \text {, daily optimised to obtain } \\
\text { maximum }{ }^{103} \mathrm{Rh} \text { signal intensity and } \\
\text { minimum oxide formation rates }\end{array}$ \\
\hline Auxiliary gas & $\begin{array}{l}\sim 0.81 \mathrm{~min}^{-1} \text { daily optimised to obtain } \\
\text { maximum }{ }^{103} \mathrm{Rh} \text { signal intensity and } \\
\text { minimum oxide formation rates }\end{array}$ \\
\hline Data acquisition & $\begin{array}{l}\text { Peak hopping mode, } 50 \text { sweeps per reading, } \\
1 \text { reading per replicate, } 3 \text { replicates, dwell } \\
\text { time } 20 \mathrm{~ms} \text { for all isotopes except } 40 \mathrm{~ms} \\
\text { for } \mathrm{Eu}, \mathrm{Tb}, \mathrm{Ho}, \mathrm{Yb} \text { and } 60 \mathrm{~ms} \text { for } \mathrm{Tm}\end{array}$ \\
\hline Sample uptake & $\sim 2 \mathrm{ml} \mathrm{\operatorname {min } ^ { - 1 }}$ \\
\hline Nebulizer & $\begin{array}{l}\mathrm{U}^{-6000 A T^{+}} \text {(Cetac Technologies, Omaha, } \\
\text { NE, USA) }\end{array}$ \\
\hline Sweep gas (argon) & $\begin{array}{l}\sim 2.851 \mathrm{~min}^{-1} \text { (depending on the condition } \\
\text { of the membrane) }\end{array}$ \\
\hline Heating temperature & $140{ }^{\circ} \mathrm{C}$ \\
\hline $\begin{array}{l}\text { Desolvation } \\
\text { temperature }\end{array}$ & $140^{\circ} \mathrm{C}$ \\
\hline Cooling temperature & $2{ }^{\circ} \mathrm{C}$ \\
\hline
\end{tabular}

summarised in Table 1, the formation of doubly charged ionsassessed via the ratio of $\mathrm{Ba}^{2+} / \mathrm{Ba}$ - amounted to about $0.3 \%$.

\section{Reagents and standards}

For the preparation of all solutions, high-purity water $(18.2 \mathrm{M} \Omega \mathrm{cm}$ ) from a Milli-Q system (Millipore, Milford, MA, USA), was used. Nitric acid (65\%, analytical-reagent grade, Merck, Darmstadt, Germany) was further purified by sub-boiling distillation (MLS GmbH). Other acids for digestions were hydrofluoric acid $\left(40 \%\right.$, Suprapur ${ }^{\circledR}$, Merck), perchloric acid $\left(70 \%\right.$, Suprapur $\left.{ }^{\mathbb{R}}\right)$, hydrochloric acid $(32 \%$, Riedel-de Haen, Seelze, Germany) and tetrafluoroboric acid solution $\left(\mathrm{HBF}_{4}, \sim 50 \%\right.$, purum, Fluka, Buchs, Switzerland). Microwave assisted digestion in the autoclave additionally required hydrogen peroxide (30\%, Baker analysed, J.T. Baker, Deventer, The Netherlands).

Calibration solutions $\left(0.2 ; 0.5 ; 1 ; 5 ; 10 \mu \mathrm{g}^{-1}\right)$ were prepared daily by adequate dilution of a multi-element stock standard solution (SPEX, Metuchen, NJ, USA, 5\% nitric acid) containing $10 \mathrm{mg} \mathrm{l}^{-1}$ of each element under investigation with $0.42 \mathrm{~mol} \mathrm{l}^{-1}$ high-purity nitric acid. To correct for instrumental drifts and plasma fluctuations all analyte solutions were spiked with a rhodium and rhenium standard solution (SPEX) to a final concentration of $5 \mu \mathrm{g}^{-1}$ of each element. Final dilution factors ranged from approximately 400 to 500 .

\section{Peat samples}

Two bulk peat samples (Peat 1 and 2) with different chemical matrix characteristics (botanical composition, degree of humification, ash content, concentrations of major elements and trace elements) were employed for the development of adequate peat digestion procedures. Peat 1 consists of a fen peat from the Holland Marsh, Ontario, Canada. This material (sample code OGS 1878P) was dried, milled, homogenised, split and bottled in 1982 by the Ontario Geological Survey and has been made available by the Geoscience Laboratories, Sudbury, Ontario.

Peat 2 was considered to serve as an internal reference material in future studies and was prepared from a peat core collected at Schöpfenwaldmoor, near Interlaken, Switzerland. The material was subjected to cryogenic milling at the Environmental Specimen Bank at the Research Centre Juelich before the powder was freeze-dried, split and bottled in 1999. Details can be found elsewhere. ${ }^{17}$ 


\section{Closed vessel acid digestion}

Heating on a hot-plate. For this low pressure digestion approach, sample aliquots of approximately $200 \mathrm{mg}$, weighed to $0.1 \mathrm{mg}$, were transferred into PTFE vessels. After addition of $2 \mathrm{ml}$ of $\mathrm{HNO}_{3}, 0.2 \mathrm{ml}$ of $\mathrm{HF}, 0.1 \mathrm{ml}$ of $\mathrm{HClO}_{4}$ and $0.2 \mathrm{ml}$ of $\mathrm{HCl}$ to the powders, the vessels were gently shaken to mix the contents, closed and placed and fixed in the steel jackets. The digestion vessels were heated for $5 \mathrm{~h}$ on a hot-plate at a temperature of $180{ }^{\circ} \mathrm{C}$. After completion, vessels were allowed to reach ambient temperature again. While the bulk solutions were always clear, these digests always revealed a small amount of precipitate. Solutions were diluted to $10 \mathrm{ml}$ using high-purity water.

High pressure asher (HPA). Aliquots of $200 \mathrm{mg}$ were weighed into each of the seven $30 \mathrm{ml}$ quartz vessels. Subsequently, only $2 \mathrm{ml}$ of high-purity nitric acid were added to each sample. The seven digestion vessels were placed in a holder. The autoclave was locked and a starting pressure of 100 bar (with $\mathrm{N}_{2}$ ) was applied to the system. The vessels were heated from room temperature to $100{ }^{\circ} \mathrm{C}$ in $15 \mathrm{~min}$, remaining at this temperature for another $30 \mathrm{~min}$, followed by increasing the temperature to $320{ }^{\circ} \mathrm{C}$ in $15 \mathrm{~min}$ and holding at $320{ }^{\circ} \mathrm{C}$ for another $90 \mathrm{~min}$. During the first gentle phase of the digestion programme, the organic, carbon-rich matrix components are slowly converted to $\mathrm{CO}_{2}$ to avoid foaming. Subsequently the heating temperature is increased to the maximum temperature of the system for dissolution of the remaining inorganic constituents of the samples. After completion of the heating cycle, the system was allowed to cool to room temperature for $1.5 \mathrm{~h}$. The pressure inside the reaction chamber was carefully released and the contents of the digestion vessels were quantitatively transferred into $15 \mathrm{ml}$ poly(propylene) tubes (Falcon ${ }^{\circledR}$, Becton Dickinson, Meylan, France). As no HF or $\mathrm{HBF}_{4}$ was used to destroy siliceous matter in the samples, these digests too were essentially clear, except for a precipitate at the bottom of the vessel.

Microwave autoclave. Sample aliquots (approx. $250 \mathrm{mg}$ ) were weighed to $0.1 \mathrm{mg}$ into $20 \mathrm{ml}$ PTFE vessels. The acid mixtures contained $3-5 \mathrm{ml}$ of $\mathrm{HNO}_{3}$ with various amounts of $\mathrm{HF}$ and $\mathrm{HBF}_{4}$ ranging from 0.05 to $1 \mathrm{ml}$. Up to 40 samples can be simultaneously digested under identical experimental conditions in the microwave autoclave. A starting pressure of 50 bar (with Ar) was applied to the reaction chamber. Vessels were then heated in the microwave autoclave for $76 \mathrm{~min}$, increasing the temperature to $240{ }^{\circ} \mathrm{C}$; during this phase the pressure in the reaction chamber reached about 120 bar. The heating programme consisted of the following steps: room temperature to $60^{\circ} \mathrm{C}$ in $9 \mathrm{~min} ; 60-125^{\circ} \mathrm{C}$ in $25 \mathrm{~min} ; 125-160{ }^{\circ} \mathrm{C}$ in $10 \mathrm{~min}$; $160-240{ }^{\circ} \mathrm{C}$ in $12 \mathrm{~min}$; holding at $240{ }^{\circ} \mathrm{C}$ for $20 \mathrm{~min}$. After cooling for about $35 \mathrm{~min}$ to well below the boiling-point of the acid mixture at atmospheric pressure, the reaction chamber was opened. All digestion solutions of peat samples contained a slight precipitate even under optimised experimental conditions. However, absolutely colourless digestion solutions were obtained which indicates efficient destruction of the organic matter. The contents of the digestion vessels were quantitatively transferred into calibrated $15 \mathrm{ml}$ poly(propylene) tubes $\left(\right.$ Falcon ${ }^{\circledR}$ ) and filled to the mark with high-purity water.

\section{Quality control}

A peat reference material with certified elemental concentrations is currently not available. Therefore, a plant reference material with certified or recommended REE concentrations (GBW 07602 Bush Branches and Leaves, Institute of Geophysical and Geochemical Exploration, Langfang, China) was analysed with every batch of samples to ensure the accuracy of the applied analytical procedures. A candidate reference material, CRM 670 Aquatic Plant, with accepted values for all REE compiled from an inter-laboratory comparison, was kindly donated by S. Hann, University of Agriculture, Vienna, Austria. Peat 1 was additionally characterised by instrumental neutron activation analysis for selected REE in a commercial laboratory (ACTLABS, Activation Laboratories Ltd., Ancaster, Ontario, Canada).

All reference materials and peat samples were used as bottled. Results were corrected for the humidity content in the powders as determined on $200 \mathrm{mg}$ aliquots of each material by an electronic moisture analyser (MA $100 \mathrm{H}$, Sartorius, Göttingen, Germany). ${ }^{18}$

\section{Results and discussion}

The mostly trivalent REE consist of the Group III B transition elements Sc, Y and $\mathrm{La}$ and inner transition elements (or lanthanides), Ce through Lu. In geochemistry, the term "rare earth elements" generally refers only to the lanthanides (La-Lu), and this well entrenched distinction from formal chemical nomenclature has been the source of confusion. Yttrium behaves similarly to the lanthanides Dy-Ho and thus is commonly included in discussions of the REE. Scandium, in contrast, is a substantially smaller cation with distinctive geochemical behaviour and thus is generally included in discussions of the first transition elements $\mathrm{Fe}, \mathrm{V}, \mathrm{Cr}, \mathrm{Co}$ and Ni. ${ }^{19}$

No certified reference material (CRM) of plant or soil origin for all REE is currently commercially available. However, the manufacturer of reference material GBW 07602 Bush Branches and Leaves provides certified concentrations for many REE; for all other REE information values are reported. To overcome this lack of available CRMs for the determination of REE, the Institute for Reference Materials and Measurements (IRMM), Geel, Belgium, organised an international certification campaign for REE in various matrices. ${ }^{20}$ One of these candidate reference materials, CRM 670 Aquatic Plant, was also used for the development of the analytical procedures described here, as "accepted" values for all REE in this material are already available. ${ }^{1}$

\section{Selection of internal standards}

Initial experiments quickly revealed that ${ }^{103} \mathrm{Rh}$, chosen as internal standard (IS), did not adequately correct for signal instabilities. The ${ }^{103} \mathrm{Rh}$ signal was strongly influenced by the matrix content of the solutions nebulised and sometimes changed by as much as $150 \%$ during a measurement sequence. The great variability of this IS signal indicates the need to select carefully an appropriate IS for the analytes of interest. A literature survey revealed considerable discrepancy in the choice of IS selected for REE analysis by ICP-MS. Prohaska et al., ${ }^{2}$ using a microconcentric nebuliser (MCN 6000), favoured ${ }^{115} \mathrm{In}$ as IS, definitely stating that $\mathrm{Ru}, \mathrm{Rh}$ and $\mathrm{Re}$ are less suited because these elements show lower signal suppression than the REE. Riondato et al., ${ }^{1}$ in turn, working with a conventional pneumatic nebuliser, used two IS, namely ${ }^{102} \mathrm{Ru}$ for Sc, Y, La, Ce, Pr, Nd, Sm and Eu, and ${ }^{187} \mathrm{Re}$ for $\mathrm{Gd}$, $\mathrm{Tb}, \mathrm{Dy}, \mathrm{Ho}, \mathrm{Er}, \mathrm{Tm}, \mathrm{Yb}$ and Lu. Some authors have used both In and $\mathrm{Rh}$, without specifying which of these was used for which REE; ${ }^{13}$ other investigators measuring REE in waters have used Re for all of the REE. ${ }^{11}$

Considering the discrepancies apparent in previous studies, all of the above-mentioned potential IS, namely ${ }^{102} \mathrm{Ru},{ }^{103} \mathrm{Rh}$, ${ }^{115} \mathrm{In}$ and ${ }^{185} \mathrm{Re}$, were tested for this purpose. Although the natural abundance of ${ }^{187} \operatorname{Re}(62.6 \%)$ is higher than that of ${ }^{185} \mathrm{Re}$ $(37.4 \%)$, we preferred to use the latter because the signal of ${ }^{187} \mathrm{Re}$ might be interfered with by osmium present in the sample (natural abundance of ${ }^{187}$ Os $1.6 \%$ ). To the best of the authors' 


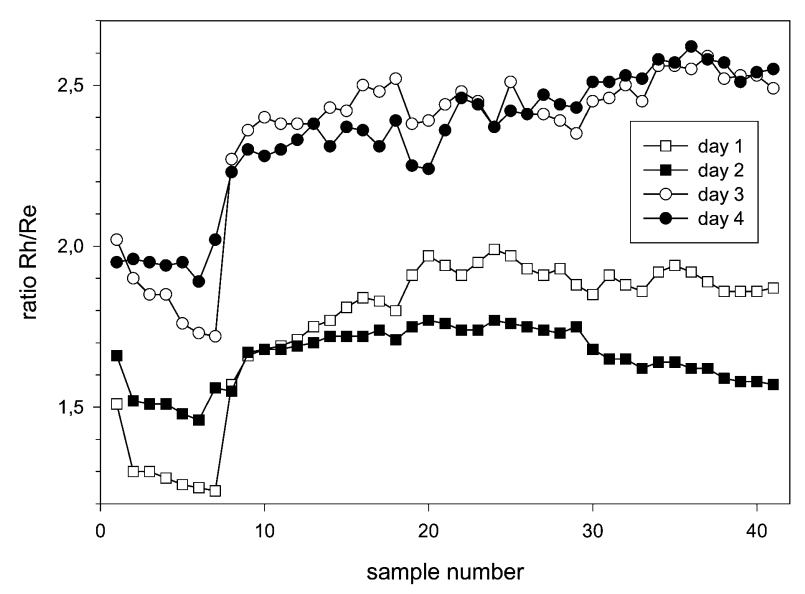

Fig. 1 Change of the ${ }^{103} \mathrm{Rh} /{ }^{185} \mathrm{Re}$ ratio $\left(5 \mu \mathrm{g} \mathrm{l}^{-1}\right.$ each, internal standards) while measuring the identical sample sequence on four different days as obtained by USN-ICP-MS.

knowledge, the technical reason for selecting one IS over another is not fully understood. However, two major theories are commonly reported. First, the ionisation energy of the IS should match as closely as possible those of the analytes of interest, and second, the IS should appear in the mass spectrum in the vicinity of the analytes. The ionisation energies (IE) for the lighter REE range between 523 and $547 \mathrm{~kJ} \mathrm{~mol}^{-1}$, whereas these values vary from 524 to $603 \mathrm{~kJ} \mathrm{~mol}^{-1}$ for the heavier REE. $^{21}$ If comparable IE is the most important factor in selecting appropriate IS, In (IE $558 \mathrm{~kJ} \mathrm{~mol}^{-1}$ ) should be the best choice. In contrast, the IE for the other potential IS are larger, namely 711,720 and $760 \mathrm{~kJ} \mathrm{~mol}^{-1}$ for $\mathrm{Ru}, \mathrm{Rh}$ and $\mathrm{Re}$, respectively. Despite these differences, however, our experiments revealed an almost identical signal response of the ICP$\mathrm{MS}$ for $\mathrm{Ru}, \mathrm{Rh}$ and In used as internal standard in the digestion solutions, whereas Re behaved differently. However, the ratio ${ }^{103} \mathrm{Rh} /{ }^{185} \mathrm{Re}$ in identical sample sequences measured on different days changed dramatically as summarised in Fig. 1. First, a decrease of the signal intensities of the internal standard was always observed during a measurement sequence which corresponded to the nebulisation of blank and standard solutions. As depicted in Fig. 1, also the ratio of $\mathrm{Rh} / \mathrm{Re}$ followed this pattern. When solutions of digested plant or peat material were nebulised, the absolute count rates for both $\mathrm{Rh}$ and $\mathrm{Re}$ increased dramatically; however, the ratio $\mathrm{Rh} / \mathrm{Re}$ also changed considerably in favour of Rh (Fig. 1). This ratio steadily increased or sometimes decreased during a measurement sequence. From these experiments it was evident that $\mathrm{Rh}$ and Re will correct ICP-MS signals for REE differently. Our studies revealed that the best agreement between experimental concentrations and certified or accepted values in reference materials was obtained when using $\mathrm{Rh}$ and $\mathrm{Re}$ as IS. The signal response of lighter REE predominantly followed the Rh signal, whereas for heavier REE the Re ICP-MS response was the decisive factor for the calculation of the results. Therefore, to compensate for this signal instability of IS and to obtain accurate and precise results, $\mathrm{Rh}$ was finally selected to correct for Sc, Y and $\mathrm{La}$, and Re for $\mathrm{Lu}$. For all other REE both Rh and Re had simultaneously to be considered.

\section{Influence of $\mathrm{HF}$ and $\mathrm{HBF}_{4}$}

Because peat and plant matrices contain various amounts of siliceous mineral phases, nitric acid alone produced digestion solutions containing precipitates. In addition to using HF in the digestion mixture to dissolve silicates, we also evaluated the potential of tetrafluoroboric acid, with the hope of combining the advantages of both $\mathrm{HF}$ and $\mathrm{H}_{3} \mathrm{BO}_{3}$.

To investigate the influence of $\mathrm{HF}$ and $\mathrm{HBF}_{4}$ in more detail,

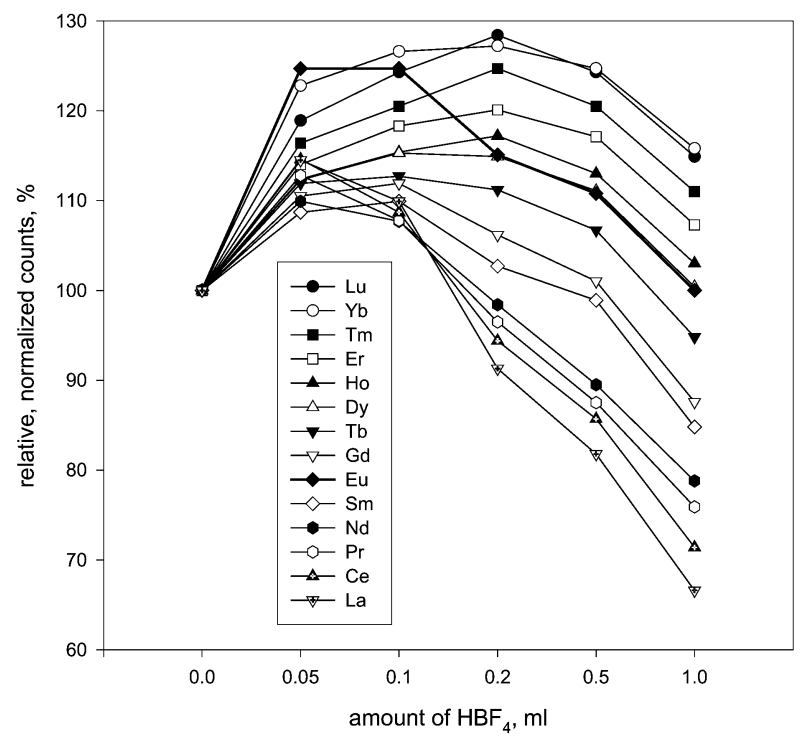

Fig. 2 Normalised ICP-MS response for REE in Peat 1 as a function of the composition of the digestion mixture $\left(\mathrm{HNO}_{3}-\mathrm{HBF}_{4}\right)$.

$250 \mathrm{mg}$ aliquots of Peat 1 were digested with $3 \mathrm{ml}$ of nitric acid and various amounts $(0,0.05,0.1,0.2,0.5$ and $1.0 \mathrm{ml})$ of both of the above-mentioned acids in the microwave autoclave. At least two replicate digestions were carried out for each acid mixture. The signal intensities of the ICP-MS measurements were normalised to sample mass and internal standard count rate. Results of the analysis of digestion solutions obtained after digestion with $3 \mathrm{ml}$ of nitric acid alone were set to $100 \%$ and all other concentrations of each REE were plotted relative to this first data point (Fig. 2). As is clearly shown in Fig. 2, the added amount of $\mathrm{HBF}_{4}$ distinctly influences the final result.

The observed fractionation of REE is much more pronounced for lighter REE than for heavier REE. In fact, looking at the sequence of the data points corresponding to $1 \mathrm{ml}$ of $\mathrm{HBF}_{4}$ (Fig. 2), the elements are inversely fractionated with respect to their position in the Periodic Table. The only exception is europium, which shows a different behaviour and possible reasons for that will be outlined later. The lanthanides decrease progressively in ionic radius from $\mathrm{La}$ to $\mathrm{Lu}$, a phenomenon known as "lanthanide contraction". It is caused by the progressively filling of the $4 \mathrm{f}$ electron orbitals, prior to $5 \mathrm{~d}$, allowing greater nuclear attraction for the valence electrons. The ionic radii of the REE decrease from $1.13 \AA$ for $\mathrm{La}^{3+}$ to $0.94 \AA$ for $\mathrm{Lu}^{3+}$ in six-fold coordination. As a result, the ionic potentials of the REE increase from $2.65 \mathrm{~nm}^{-1}$ $\left(\mathrm{La}^{3+}\right)$ to $3.19 \mathrm{~nm}^{-1}\left(\mathrm{Lu}^{3+}\right)$, which suggests that $\mathrm{Lu}^{3+}$ forms stronger ionic bonds in crystals than $\mathrm{La}^{3+} \cdot{ }^{22}$ Having said this, it is evident from Fig. 2 that REE forming ionic bonds are less affected as regards fractionation than those REE tending to form more covalent-like bonds. This finding is in accordance with the tendency of solubility products of lanthanide fluorides. ${ }^{23}$ Fraústo da Silva and Queimado ${ }^{23}$ found the following stoichiometric values $\left[\mathrm{mol}^{4} \mathrm{1}^{-4}\right]$ at $25{ }^{\circ} \mathrm{C}: 1.19 \times$ $10^{-19}\left(\mathrm{LaF}_{3}\right), 5.58 \times 10^{-20}\left(\mathrm{CeF}_{3}\right), 1.09 \times 10^{-19}\left(\mathrm{PrF}_{3}\right)$, $2.36 \times 10^{-15}\left(\mathrm{NdF}_{3}\right), 1.01 \times 10^{-18}\left(\mathrm{SmF}_{3}\right), 5.98 \times 10^{-18}$ $\left(\mathrm{EuF}_{3}\right), 1.58 \times 10^{-17}\left(\mathrm{GdF}_{3}\right), 1.85 \times 10^{-17}\left(\mathrm{TbF}_{3}\right), 4.67 \times$ $10^{-17}\left(\mathrm{DyF}_{3}\right), 1.33 \times 10^{-16}\left(\mathrm{HoF}_{3}\right), 2.96 \times 10^{-16}\left(\mathrm{ErF}_{3}\right)$, $1.50 \times 10^{-16}\left(\mathrm{TmF}_{3}\right), 9.62 \times 10^{-16}\left(\mathrm{YbF}_{3}\right), 8.42 \times 10^{-16}$ $\left(\mathrm{LuF}_{3}\right)$. Fig. 3 highlights the favourable correlation of the normalised ICP-MS response established for Peat 1 (values from the determination of REE in digestion solutions with $3 \mathrm{ml}$ of $\mathrm{HNO}_{3}$ and $0.1 \mathrm{ml}$ of $\mathrm{HBF}_{4}$ relative to results from the analysis of digestion solutions containing only $3 \mathrm{ml}$ of $\mathrm{HNO}_{3}$, compare with Fig. 2) with the solubility products of the REE trifluorides expressed as their corresponding $\mathrm{p} K_{\mathrm{s}}$ values. 


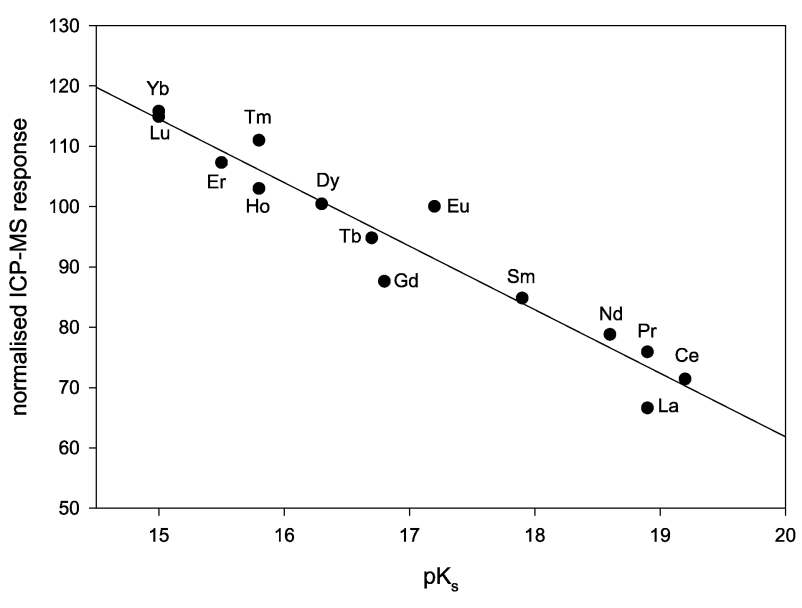

Fig. 3 Correlation between normalised ICP-MS response for REE in Peat 1 and the solubility products of the REE trifluorides (as $\mathrm{p} K_{\mathrm{s}}$ ).

The results of the analysis of Peat 1 digested with acid mixtures containing 0.05 and $0.1 \mathrm{ml}$ of $\mathrm{HF}$, respectively, were very similar to those obtained with the same amount of $\mathrm{HBF}_{4}$. However, further increasing the volumes of HF led to a dramatic reduction in the concentration of REE found in the digestion solutions. Owing to the formation of REE fluorides, at volumes of $1 \mathrm{ml}$ of $\mathrm{HF}$, only approximately $1 \%$ of the analytes could be quantified. These data clearly show that the selection of appropriate amounts of HF for digestion of peat is critical. Although the same tendency can be observed for $\mathrm{HBF}_{4}$ (Fig. 2), the negative influence of "excess" of $\mathrm{HBF}_{4}$ is much less pronounced than that for HF. For digests containing $1 \mathrm{ml}$ of $\mathrm{HBF}_{4}$, in the worst case (La, Ce), still about $70 \%$ of the signal intensities relative to those of solutions digested with $\mathrm{HNO}_{3}$ alone were obtained.

As is clearly demonstrated above, $\mathrm{HBF}_{4}$ is preferable to $\mathrm{HF}$ as a component of the digestion mixture for the mineralisation of peat and plant matrices, for several reasons. First, the destructive power of $\mathrm{HBF}_{4}$ and $\mathrm{HF}$ for silicates is comparable, but the tolerance for "excess of acid" is much more pronounced for $\mathrm{HBF}_{4}$. Second, the cost of HF of Suprapur ${ }^{\circledR}$ quality is distinctly higher than that of the analytical-reagent grade purity of $\mathrm{HBF}_{4}$ used in this study. Contributions of both acids ( $\mathrm{HF}$ and $\mathrm{HBF}_{4}$ ) to blank levels of REE were virtually identical and were at or close to the noise level of the ICP-MS detector. In general, blank concentrations were at least 100 times lower than actual concentrations of REE quantified in the digestion solutions. Finally, handling HF is potentially much more dangerous than using $\mathrm{HBF}_{4}$; therefore, the latter is preferable for safety reasons.

Although the reaction mechanism of $\mathrm{HBF}_{4}$ with silicates is complex and not fully elucidated, it is assumed that $\mathrm{HBF}_{4}$ hydrolyses to $\mathrm{F}^{-}, \mathrm{BF}_{3} \mathrm{OH}$ and $\mathrm{BF}_{2}(\mathrm{OH})_{2}$ in aqueous solution, ${ }^{24}$ thus liberating fluoride for the conversion of silicates in the samples to gaseous $\mathrm{SiF}_{4}$. The thermodynamic equilibrium of this reaction is dependent on the temperature of the solution and concentration of $\mathrm{HBF}_{4}$. However, because of the complex reaction mechanisms involved, the final concentrations of the various fluoride compounds in the digestion solution are difficult to predict. Experimental studies have shown that the kinetically controlled reaction between $\mathrm{HF}$ and well crystallised quartz (geogenic origin) is much slower than the reaction of HF with silicates. ${ }^{16}$ This also holds true for $\mathrm{HBF}_{4}$, which can therefore be employed to separate quartz from silicates. ${ }^{16}$ Given the duration of the autoclave digestion procedure described here, the temperature, pressure, and concentration of acids employed, we assume that quartz too, is completely decomposed.

\section{REE in reference materials}

After initial experiments showing the significant influence of $\mathrm{HF}$ and $\mathrm{HBF}_{4}$ in the digestion mixture as well as that of the internal standard on the final results (Fig. 1 and 2), three digestion procedures were applied to the only plant reference material commercially available for REE analysis (Table 2). For digestions in the HPA, quartz vessels were available which precluded the use of $\mathrm{HF}$ or $\mathrm{HBF}_{4}$, but allowed a temperature of $320{ }^{\circ} \mathrm{C}$ to be applied to the mineralisation of the samples. However, a comparison with certified or information values indicated that the silicate fraction of this plant material contained a significant amount of REE which are not released from the silicates when using only $\mathrm{HNO}_{3}$ during digestions. Consequently, although the temperature in the HPA was distinctly higher than that applied in the other two digestion procedures, the measured REE concentrations were mostly below the accepted and information values (Table 2). Mainly owing to the addition of $\mathrm{HF}$ to the digestion mixture, the situation was slightly improved when the closed-pressurised system operated on a hot-plate at $180{ }^{\circ} \mathrm{C}$ was employed. However, some REE concentrations quantified were lower

Table 2 Concentrations of REE as determined in the reference material GBW 07602 Bush Branches and Leaves by USN-ICP-MS after various sample digestion procedures (mean \pm standard deviation)

\begin{tabular}{|c|c|c|c|c|c|}
\hline \multirow[b]{2}{*}{ Isotope } & \multirow[b]{2}{*}{ Units } & \multicolumn{3}{|c|}{ Closed pressurised digestion ${ }^{a}$} & \multirow[b]{2}{*}{ Certified $^{b}$} \\
\hline & & $\begin{array}{l}\text { On hot-plate } \\
N=10\end{array}$ & $\begin{array}{l}\text { In high pressure } \\
\text { asher } N=2\end{array}$ & $\begin{array}{l}\text { In microwave } \\
\text { autoclave } N=40\end{array}$ & \\
\hline${ }^{139} \mathrm{La}$ & $\mu \mathrm{g} \mathrm{g}^{-1}$ & $1.16 \pm 0.03$ & $1.01 \pm 0.05$ & $1.37 \pm 0.08$ & $1.23 \pm 0.07$ \\
\hline${ }^{140} \mathrm{Ce}$ & $\mu \mathrm{g} \mathrm{g}^{-1}$ & $2.41 \pm 0.05$ & $2.01 \pm 0.01$ & $2.50 \pm 0.09$ & $2.40 \pm 0.20$ \\
\hline${ }^{141} \mathrm{Pr}$ & $\mathrm{ng} \mathrm{g}^{-1}$ & $282 \pm 7$ & $237 \pm 1$ & $283 \pm 11$ & $(210)^{-2.20}$ \\
\hline${ }^{144} \mathrm{Nd}$ & $\mu \mathrm{g} \mathrm{g} \mathrm{g}^{-1}$ & $1.02+0.03$ & $0.87+0.01$ & $1.05+0.04$ & (1.1) \\
\hline${ }^{152} \mathrm{Sm}$ & $\mathrm{ng} \mathrm{g}^{-1}$ & $189 \pm 5$ & $167 \pm 1$ & $193 \pm 7$ & $190 \pm 10$ \\
\hline${ }^{153} \mathrm{Eu}$ & $\operatorname{ng~g}^{-1}$ & $37.1 \pm 1.6$ & $32.3 \pm 0.6$ & $36.8 \pm 1.0$ & $37 \pm 2$ \\
\hline${ }^{158} \mathrm{Gd}$ & $\mathrm{ng} \mathrm{g}^{-1}$ & $153 \pm 3$ & $143 \pm 1$ & $170 \pm 6$ & $(180)^{--}$ \\
\hline${ }^{159} \mathrm{~Tb}$ & $\mathrm{ng} \mathrm{g}^{-1}$ & $21.2 \pm 0.9$ & $20.7 \pm 0.4$ & $24.0 \pm 0.8$ & (26) \\
\hline${ }^{164} \mathrm{Dy}$ & $\mathrm{ng} \mathrm{g}^{-1}$ & $119 \pm 3$ & $110 \pm 1$ & $138 \pm 4$ & (120) \\
\hline${ }^{165} \mathrm{Ho}$ & $\mathrm{ng} \mathrm{g}^{-1}$ & $21.3 \pm 0.8$ & $20.9 \pm 0.6$ & $26.4 \pm 0.8$ & (27) \\
\hline${ }^{166} \mathrm{Er}$ & $\operatorname{ng~g~}^{-1}$ & $56.9 \pm 2.8$ & $52.8 \pm 0.4$ & $73 \pm 3$ & (60) \\
\hline${ }^{169} \mathrm{Tm}$ & $\operatorname{ng~g~}^{-1}$ & $7.7+0.4$ & $8.0+0.7$ & $10.4+0.3$ & $(\sim 8)$ \\
\hline${ }^{174} \mathrm{Yb}$ & $\operatorname{ng~g~}^{-1}$ & $47.3 \pm 2.0$ & $44.3 \pm 0.9$ & $66 \pm 3$ & $63 \pm 11$ \\
\hline${ }^{175} \mathrm{Lu}$ & $\operatorname{ng~g~}^{-1}$ & $6.4 \pm 0.3$ & $6.8 \pm 0.5$ & $10.6 \pm 0.3$ & $(12)^{-}$ \\
\hline
\end{tabular}

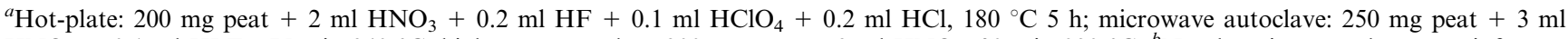
$\mathrm{HNO}_{3}+0.1 \mathrm{ml} \mathrm{HBF}, 75 \mathrm{~min} 240{ }^{\circ} \mathrm{C}$; high pressure asher: $200 \mathrm{mg}$ peat $+2 \mathrm{ml} \mathrm{HNO}, 90 \mathrm{~min} 320{ }^{\circ} \mathrm{C}$. ${ }^{b}$ Numbers in parentheses are information values only. 
Table 3 Influence of $\mathrm{HF}$ and $\mathrm{HBF}_{4}$ in the digestion mixture on the results of REE in the candidate reference material CRM 670 Aquatic Plant as determined by acid digestion in the microwave autoclaveUSN-ICP-MS. Concentrations in $\mathrm{ng} \mathrm{g}^{-1}$, mean \pm standard deviation

\begin{tabular}{|c|c|c|c|c|}
\hline \multirow[b]{2}{*}{ Isotope } & \multicolumn{3}{|c|}{ Digestion mixture } & \multirow[b]{2}{*}{$\begin{array}{l}\text { Accepted } \\
\text { value }\end{array}$} \\
\hline & $\begin{array}{l}3 \mathrm{ml} \mathrm{HNO}_{3} \\
N=12\end{array}$ & $\begin{array}{l}3 \mathrm{ml} \mathrm{HNO}_{3}+ \\
0.1 \mathrm{ml} \mathrm{HF} \\
N=12\end{array}$ & $\begin{array}{l}3 \mathrm{ml} \mathrm{HNO}_{3}+ \\
0.1 \mathrm{ml} \mathrm{HBF}_{4} \\
N=12\end{array}$ & \\
\hline${ }^{45} \mathrm{Sc}$ & $241 \pm 52$ & $279 \pm 36$ & $347 \pm 37$ & $190 \pm 11$ \\
\hline${ }^{89} \mathrm{Y}$ & $442 \pm 25$ & $493 \pm 37$ & $507 \pm 33$ & $470 \pm 40$ \\
\hline${ }^{139} \mathrm{La}$ & $552 \pm 47$ & $583 \pm 82$ & $577 \pm 74$ & $487 \pm 28$ \\
\hline${ }^{140} \mathrm{Ce}$ & $993 \pm 42$ & $1029 \pm 60$ & $1063 \pm 55$ & $980 \pm 50$ \\
\hline${ }^{141} \mathrm{Pr}$ & $119 \pm 6$ & $125 \pm 8$ & $128 \pm 7$ & $121 \pm 6$ \\
\hline${ }^{144} \mathrm{Nd}$ & $465 \pm 21$ & $472 \pm 26$ & $482 \pm 27$ & $476 \pm 15$ \\
\hline${ }^{152} \mathrm{Sm}$ & $94 \pm 4$ & $97 \pm 6$ & $98 \pm 6$ & $94 \pm 8$ \\
\hline${ }^{153} \mathrm{Eu}$ & $21 \pm 1$ & $22 \pm 2$ & $23 \pm 2$ & $23 \pm 3$ \\
\hline${ }^{158} \mathrm{Gd}$ & $89 \pm 3$ & $92 \pm 4$ & $94 \pm 4$ & $96 \pm 9$ \\
\hline${ }^{159} \mathrm{~Tb}$ & $12.4 \pm 0.5$ & $13.0 \pm 0.6$ & $13.3 \pm 0.6$ & $13.7 \pm 1.3$ \\
\hline${ }^{164}$ Dy & $71 \pm 3$ & $77 \pm 4$ & $78 \pm 4$ & $79 \pm 7$ \\
\hline${ }^{165} \mathrm{Ho}$ & $13.5 \pm 0.5$ & $15.0 \pm 0.8$ & $15.2 \pm 0.6$ & $15.8 \pm 1.7$ \\
\hline${ }^{166} \mathrm{Er}$ & $36 \pm 2$ & $42 \pm 3$ & $43 \pm 2$ & $43 \pm 2$ \\
\hline${ }^{169} \mathrm{Tm}$ & $4.9 \pm 0.2$ & $5.9 \pm 0.2$ & $5.9 \pm 0.2$ & $5.7 \pm 0.5$ \\
\hline${ }^{174} \mathrm{Yb}$ & $31 \pm 2$ & $38 \pm 3$ & $38 \pm 2$ & $40 \pm 3$ \\
\hline${ }^{175} \mathrm{Lu}$ & $4.8 \pm 0.2$ & $6.1 \pm 0.3$ & $6.2 \pm 0.3$ & $6.0 \pm 0.8$ \\
\hline
\end{tabular}

than the expected values. This holds especially true for Gd, Tb, $\mathrm{Ho}, \mathrm{Yb}$ and $\mathrm{Lu}$. The best agreement between experimentally determined concentrations and reported values was obtained when samples were digested with the microwave autoclave employing $\mathrm{HNO}_{3}$ and $\mathrm{HBF}_{4}$. In these (microwave autoclave) digestions, ICP-MS measurements yielded the highest concentrations of REE, indicating that the destructive power of the microwave autoclave approach provides the harshest conditions. However, still some discrepancies remained between the results obtained by the microwave autoclave $/ \mathrm{HNO}_{3}-\mathrm{HBF}_{4}$ approach and a few indicative values ( $\mathrm{Pr}, \mathrm{Dy}, \mathrm{Er}, \mathrm{Tm})$ reported for GBW 07602. As these indicative values are based on only two analytical results, the reported concentrations have to be considered with caution.

In this context, the determination of REE in the candidate reference material CRM 670 Aquatic Plant was of great assistance in solving this evaluation dilemma (Table 3). Applying the microwave autoclave with $3 \mathrm{ml}$ of $\mathrm{HNO}_{3}$ and $0.1 \mathrm{ml}$ of $\mathrm{HBF}_{4}$, again experimental and accepted values, including Pr, Dy, Er and Tm, compared very well. For La, however, higher concentrations than the accepted value and large standard deviations were observed in this material, the reason for which is presently unknown (Table 3). As this plant material contains only a small amount of silicates, digestions carried out with $\mathrm{HNO}_{3}$ provided in most cases results within the range of the uncertainty reported for the accepted values, although these results were always lower than those obtained with $\mathrm{HNO}_{3}-\mathrm{HF}$ or $\mathrm{HNO}_{3}-\mathrm{HBF}_{4}$ mixtures, respectively.

The reliable determination of Sc and Y by ICP-MS is known to be critical as many spectral interferences hamper this endeavour. ${ }^{1,2}$ To evaluate the potential of USN in combination with membrane desolvation to help in quantifying these elements, results for Sc and $\mathrm{Y}$ are included in Table 3. As expected, results for $\mathrm{Sc}$ were characterised by high uncertainties and unacceptably elevated results compared with the expected value. $\mathrm{HF}$ and $\mathrm{HBF}_{4}$ containing digestion mixtures introduce polyatomic interferences such as $\mathrm{H}_{2}{ }^{16} \mathrm{O}_{2}{ }^{10} \mathrm{~B},{ }^{14} \mathrm{~N}^{11} \mathrm{~B}^{19} \mathrm{~F}$ and $\mathrm{H}^{16} \mathrm{O}_{2}{ }^{11} \mathrm{~B}$ in addition to the well established ones involving $\mathrm{Ca}$ and $\mathrm{Si}$, leading to even higher results as demonstrated in Table 3. For $Y$ the situation is much better and good agreement between experimental and accepted concentrations could be established. Although concentrations of $\mathrm{Y}$ determined in all kinds of digestion solutions overlapped with the accepted value, a statistically significant difference $(p<0.001)$ between the distribution of $\mathrm{Y}$ concentrations in digestions with $\mathrm{HNO}_{3}$
Table 4 Comparison of results for REE in Peat 1 (OGS 1878 P) as obtained by USN-ICP-MS after application of different digestion procedures and by neutron activation analysis, mean \pm standard deviation

\begin{tabular}{|c|c|c|c|c|}
\hline \multirow[b]{2}{*}{ Isotope } & \multirow[b]{2}{*}{ Units } & \multicolumn{2}{|c|}{ Closed pressurised digestion ${ }^{a}$} & \multirow[b]{2}{*}{$\begin{array}{l}\text { INAA }^{b} \\
N=15\end{array}$} \\
\hline & & $\begin{array}{l}\text { On hot-plate } \\
N=25\end{array}$ & $\begin{array}{l}\text { In microwave } \\
\text { autoclave } \\
N=20\end{array}$ & \\
\hline${ }^{139} \mathrm{La}$ & $\mu \mathrm{g} \mathrm{g}^{-1}$ & $4.33 \pm 0.23$ & $4.30 \pm 0.54$ & $4.7 \pm 0$ \\
\hline${ }^{140} \mathrm{Ce}$ & $\mu \mathrm{g} \mathrm{g}^{-1}$ & $9.60 \pm 0.53$ & $8.65 \pm 0.53$ & $7.3 \pm 1.5$ \\
\hline${ }^{141} \mathrm{Pr}$ & $\mu \mathrm{g} \mathrm{g}^{-1}$ & $1.17 \pm 0.06$ & $1.07 \pm 0.24$ & $-^{-}$ \\
\hline${ }^{144} \mathrm{Nd}$ & $\mu \mathrm{g} \mathrm{g}^{-1}$ & $4.26 \pm 0.21$ & $4.05 \pm 0.27$ & $3.7 \pm 0.6$ \\
\hline${ }^{152} \mathrm{Sm}$ & $\operatorname{ng~g}^{-1}$ & $776 \pm 35$ & $766 \pm 36$ & $740 \pm 70$ \\
\hline${ }^{153} \mathrm{Eu}$ & $\mathrm{ng} \mathrm{g}^{-1}$ & $162 \pm 2$ & $176 \pm 8$ & $162 \pm 38$ \\
\hline${ }^{158} \mathrm{Gd}$ & $\operatorname{ng~g}^{-1}$ & $635 \pm 27$ & $692 \pm 30$ & $-^{--}$ \\
\hline${ }^{159} \mathrm{~Tb}$ & $\mathrm{ng} \mathrm{g}^{-1}$ & $90 \pm 4$ & $102 \pm 5$ & $\complement^{c}$ \\
\hline${ }^{164} \mathrm{Dy}$ & $\operatorname{ng~g~}^{-1}$ & $544 \pm 23$ & $626 \pm 27$ & $-^{c}$ \\
\hline${ }^{165} \mathrm{Ho}$ & $\operatorname{ng~g}^{-1}$ & $106 \pm 4$ & $128 \pm 6$ & $\complement^{c}$ \\
\hline${ }^{166} \mathrm{Er}$ & $\mathrm{ng} \mathrm{g}^{-1}$ & $303 \pm 10$ & $373 \pm 18$ & $ـ^{c}$ \\
\hline${ }^{169} \mathrm{Tm}$ & $\mathrm{ng} \mathrm{g}^{-1}$ & $43 \pm 2$ & $54 \pm 3$ & $ـ^{c}$ \\
\hline${ }^{174} \mathrm{Yb}$ & $\mathrm{ng} \mathrm{g}^{-1}$ & $291 \pm 11$ & $356 \pm 21$ & $440 \pm 80$ \\
\hline${ }^{175} \mathrm{Lu}$ & $\operatorname{ng~g}^{-1}$ & $40 \pm 1$ & $58 \pm 3$ & $76 \pm 8$ \\
\hline
\end{tabular}

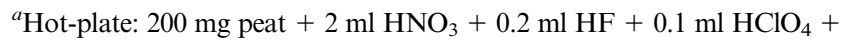
$0.2 \mathrm{ml} \mathrm{HCl}, 5 \mathrm{~h}, 180{ }^{\circ} \mathrm{C}$; microwave autoclave: $250 \mathrm{mg}$ peat $+3 \mathrm{ml}$ $\mathrm{HNO}_{3}+0.1 \mathrm{ml} \mathrm{HBF}_{4}, 75 \mathrm{~min}, 240{ }^{\circ} \mathrm{C} .{ }^{b}$ Instrumental neutron activation analysis, commercial company (ACTLABS, Activation Laboratories Ltd., Ancaster, Ontario, Canada). ' Not determined.

alone and both $\mathrm{HF}$ or $\mathrm{HBF}_{4}$ containing digests could be established. It should be noted that conventional pneumatic nebulisation yielded $\mathrm{Sc}$ and $\mathrm{Y}$ concentrations about ten and five times higher than accepted values, respectively. However, for both elements the problems of the accuracy of the obtained results as well as the high risk of the occurrence of spectral interferences exclude the possibility of measuring Sc and $\mathrm{Y}$ on a routine basis using quadrupole ICP-MS. Therefore, the findings documented in Table 3 may not be representative for ICP-MS analysis of Sc and Y and do not represent an endorsement of this approach for both elements.

\section{REE in the two peat matrices}

The digestion procedures evaluated here were applied to the dissolution of two peat matrices (Tables 4 and 5). In general, digestions both in closed vessels on a hot-plate and in the microwave autoclave yielded comparable concentrations for Peat 1 (Table 4). However, concentrations from Gd through $\mathrm{Lu}$ of digestion solutions obtained by the hot-plate digestion system were distinctly lower than corresponding REE values established by ICP-MS analysis of solutions from the microwave autoclave. A comparison with INAA results obtained from a commercial laboratory largely confirmed the concentrations obtained by the microwave autoclave-ICP-MS approach. However, a large spread of the results, not only between the two digestion-ICP-MS procedures, but also between ICP-MS and INAA, was observed for $\mathrm{Yb}$ and $\mathrm{Lu}$.

The data in Table 5 display the significant impact of the choice of the digestion mixture. Generally, nitric acid alone yielded results that were lower than $\mathrm{HBF}_{4}$ containing digests, no matter which autoclave was used for sample digestion; these digestion solutions always contained abundant precipitates, presumably silicates. The addition of only $0.1 \mathrm{ml}$ of $\mathrm{HF}$ to the digestion mixture already influenced the results obtained by ICP-MS in a severe, negative manner (Table 5). Because of the fractionation described earlier (Fig. 2), the lighter REE are especially impacted, whereas heavier REE give higher results than in $\mathrm{HNO}_{3}$ alone. It should be noted that, as regards Peat 1 (Table 4), which contains a distinctly higher concentration of silicates than Peat 2, $0.1 \mathrm{ml} \mathrm{HF}$ and $0.1 \mathrm{ml} \mathrm{HBF}_{4}$ digests yielded comparable results. These data again demonstrate that $\mathrm{HF}$ is 
Table 5 Dependence of the composition of the digestion mixture on the concentrations of REE in Peat 2 as determined by USN-ICP-MS, mean \pm standard deviation

\begin{tabular}{|c|c|c|c|c|c|}
\hline \multirow[b]{2}{*}{ Isotope } & \multirow[b]{2}{*}{ Units } & \multicolumn{4}{|c|}{ Digestion carried out in } \\
\hline & & $\begin{array}{l}\text { High pressure asher, } \\
2 \mathrm{ml} \mathrm{HNO}_{3}, N=8\end{array}$ & $\begin{array}{l}\text { Microwave autoclave, } \\
3 \mathrm{ml} \mathrm{HNO}_{3}, N=14\end{array}$ & $\begin{array}{l}\text { Microwave autoclave, } \\
3 \mathrm{ml} \mathrm{HNO}_{3}+0.1 \mathrm{ml} \\
\mathrm{HF}, N=14\end{array}$ & $\begin{array}{l}\text { Microwave autoclave, } \\
3 \mathrm{ml} \mathrm{HNO}_{3}+0.1 \mathrm{ml} \\
\mathrm{HBF}_{4}, N=14\end{array}$ \\
\hline${ }^{139} \mathrm{La}$ & $\mu \mathrm{g} \mathrm{g}^{-1}$ & $1.43 \pm 0.03$ & $1.60 \pm 0.17$ & $1.05 \pm 0.24$ & $1.84 \pm 0.18$ \\
\hline${ }^{140} \mathrm{Ce}$ & $\mu \mathrm{g} \mathrm{g}^{-1}$ & $2.90 \pm 0.14$ & $2.94 \pm 0.16$ & $2.19 \pm 0.33$ & $3.44 \pm 0.15$ \\
\hline${ }^{141} \operatorname{Pr}$ & $n g \mathrm{~g}^{-1}$ & $334 \pm 9$ & $334 \pm 17$ & $263 \pm 34$ & $387 \pm 18$ \\
\hline${ }^{144} \mathrm{Nd}$ & $\mu \mathrm{g} \mathrm{g}^{-1}$ & $1.24 \pm 0.02$ & $1.24 \pm 0.07$ & $0.99 \pm 0.12$ & $1.41 \pm 0.07$ \\
\hline${ }^{152} \mathrm{Sm}$ & $n g \mathrm{~g}^{-1}$ & $228 \pm 4$ & $225 \pm 13$ & $184 \pm 18$ & $250 \pm 11$ \\
\hline${ }^{153} \mathrm{Eu}$ & $\operatorname{ng} \mathrm{g}^{-1}$ & $47 \pm 1$ & $46 \pm 3$ & $38 \pm 3$ & $51 \pm 2$ \\
\hline${ }^{158} \mathrm{Gd}$ & $n g \mathrm{~g}^{-1}$ & $188 \pm 6$ & $189 \pm 10$ & $150 \pm 15$ & $207 \pm 7$ \\
\hline${ }^{159} \mathrm{~Tb}$ & $n g \mathrm{~g}^{-1}$ & $27 \pm 1$ & $26 \pm 2$ & $23 \pm 2$ & $30 \pm 2$ \\
\hline${ }^{164}$ Dy & $\mathrm{ng} \mathrm{g}^{-1}$ & $153 \pm 6$ & $151 \pm 9$ & $141 \pm 12$ & $174 \pm 8$ \\
\hline${ }^{165} \mathrm{Ho}$ & $n g \mathrm{~g}^{-1}$ & $29 \pm 1$ & $28 \pm 2$ & $28 \pm 2$ & $34 \pm 1$ \\
\hline${ }^{166} \mathrm{Er}$ & ng g $\mathrm{g}^{-1}$ & $78 \pm 4$ & $76 \pm 4$ & $81 \pm 6$ & $97 \pm 4$ \\
\hline${ }^{169} \mathrm{Tm}$ & $n g \mathrm{~g}^{-1}$ & $10.8 \pm 0.5$ & $10.3 \pm 0.6$ & $11.9 \pm 0.8$ & $13.9 \pm 0.6$ \\
\hline${ }^{174} \mathrm{Yb}$ & $n g \mathrm{~g}^{-1}$ & $67 \pm 4$ & $62 \pm 4$ & $78 \pm 6$ & $89 \pm 5$ \\
\hline${ }^{175} \mathrm{Lu}$ & $n g \mathrm{~g}^{-1}$ & $9.0 \pm 0.4$ & $9.4 \pm 0.4$ & $12.1 \pm 0.8$ & $14.3 \pm 0.4$ \\
\hline
\end{tabular}

a poor choice for the destruction of siliceous matter in samples which will subsequently be analysed for REE. As observed for all other samples investigated in this study, the optimised acid mixture containing $3 \mathrm{ml}$ of $\mathrm{HNO}_{3}$ and $0.1 \mathrm{ml}$ of $\mathrm{HBF}_{4}$ digested in the microwave autoclave gave the highest results for REE in Peat 2. These values also agreed fairly well with results obtained by INAA (not shown).

\section{Normalisation of lanthanide abundances}

The absolute concentration of lanthanide elements is highly variable in nature. For a comparison of REE concentrations determined in various samples, chondritic meteorites are used as a reference because they represent REE in their relative abundances in the primordial Earth. Accordingly, it is customary to display lanthanide data as a plot of chondriticnormalised values (on a logarithmic scale) versus atomic number or ionic radius (on a linear scale). Normalisation of results is achieved by division of the quantified REE concentrations in a sample by the corresponding values of chondritic meteorites. ${ }^{25}$ This is an excellent tool to monitor anthropogenic REE contamination and/or to check the validity of the employed analytical procedure. The chrondritic-normalised ratios should result in a smooth curve on a logarithmic scale, except for $\mathrm{Ce}$ and $\mathrm{Eu}$, which might display a different behaviour. The redox geochemistry and behaviour of both elements differs distinctly from the other REE and therefore might lead to anomalous REE patterns. ${ }^{19}$ Fig. 4 depicts the

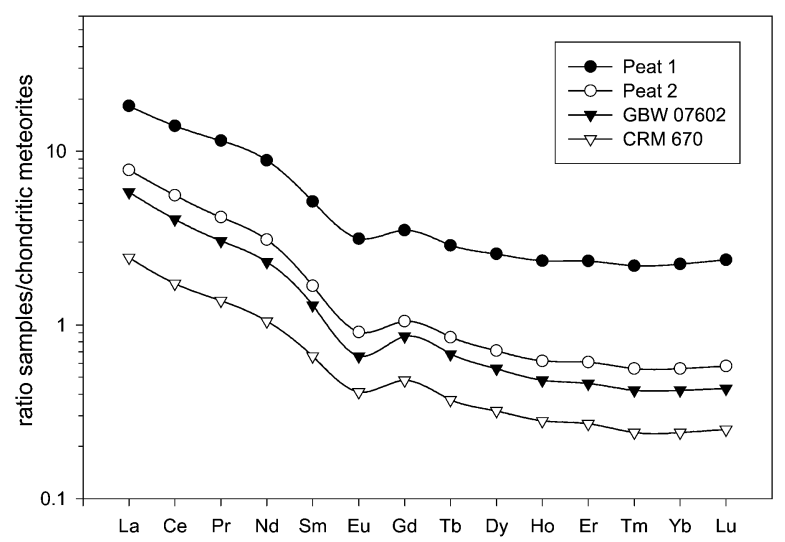

Fig. 4 Chondritic-normalised plots for the matrices investigated by digestion in the microwave autoclave and subsequent determination of REE by USN-ICP-MS. Concentrations of REE in chondritic meteorites are taken from ref. 24. chondrite-normalised REE ratios for the four matrices investigated. This figure clearly shows that for each of the curves a general continuous trend is found, except for a minimum in Eu values. This "negative Eu anomaly" is typical of the Earth's upper continental crust ${ }^{26}$ which is, ultimately, the source of REE in plants. However, the experimental Eu concentrations in the four materials agree very well with reference values (Tables 2-4). Additionally, Fig. 4 highlights the potential of normalising divergent absolute REE concentrations in various matrices by their corresponding REE values in chondritic meteorites, thus making results easily comparable. This normalisation certainly supports the interpretation of systematic REE determinations in geological matrices, for example.

\section{Comparison of digestion devices}

The three digestion devices evaluated in this study were operated at different maximum temperatures. The hot-plate system was heated to $180{ }^{\circ} \mathrm{C}$, the microwave autoclave to $240{ }^{\circ} \mathrm{C}$, and the high pressure asher to $320{ }^{\circ} \mathrm{C}$. The results for REE obtained after analysing these digestion solutions by ICPMS showed that the temperature during digestion is not the decisive factor of the entire analytical procedure, but rather that the composition of the digestion mixture $\left(\mathrm{HNO}_{3}\right.$ alone or $\mathrm{HNO}_{3}$ plus various amounts of $\mathrm{HF}$ or $\mathrm{HBF}_{4}$ ) is far more important to digest the sample completely.

As regards sample throughput, the microwave heated autoclave is by far the most efficient procedure; up to 40 samples can be digested simultaneously in a $2 \mathrm{~h}$ run, including the time needed to cool the vessels to below the boiling-point of the acid mixtures. Seven samples can be digested simultaneously in the HPA, while 8-16 closed-pressurised vessels can be placed on the home-made hot-plate. Similar to the HPA (max. temperature $320{ }^{\circ} \mathrm{C}$ ), the microwave autoclave can also be heated to $300{ }^{\circ} \mathrm{C}$. However, at temperatures above $270{ }^{\circ} \mathrm{C}$ vessels made from modified PTFE begin to soften and consequently quartz vessels have to be employed, no matter which autoclave is used, thereby precluding the use of HF or $\mathrm{HBF}_{4}$. The HPA heats the entire metal reaction chamber to the maximum temperature selected $\left(320^{\circ} \mathrm{C}\right)$ and therefore needs a longer time to cool down than the microwave autoclave before the pressure inside the reaction chamber can be released. In turn, microwave energy is directly coupled into the acid-sample mixture in the microwave autoclave, which leads to a very fast and efficient heating of the acid mixture. As a consequence, the temperature of the pressurised stainless-steel chamber of the microwave autoclave, which is additionally cooled by a chiller, is not normally heated to more than $50{ }^{\circ} \mathrm{C}$. This much lower 
temperature leads to shorter cooling times for the microwave autoclave compared with the HPA. The hot-plate system was always operated overnight because of the long time required for heating and cooling $(>7 \mathrm{~h}$ ). Another advantage of the microwave autoclave is the fact that $\mathrm{H}_{2} \mathrm{O}_{2}$ - which is used to re-oxidise nitrous gases produced during digestion to $\mathrm{HNO}_{3}$, thereby reducing the pressure inside the reaction chamber-is not directly added to each digestion vessel (as is common practice in conventional microwave digestion procedures) but can be added to a PTFE vessel which is placed in the reaction chamber. In this way $\mathrm{H}_{2} \mathrm{O}_{2}$ is distilled into the digestion vessels avoiding direct contact of the native $\mathrm{H}_{2} \mathrm{O}_{2}$ with the samples. Therefore, analytical-reagent grade $\mathrm{H}_{2} \mathrm{O}_{2}$ can be used instead of high-purity $\mathrm{H}_{2} \mathrm{O}_{2}$, which is considerably more expensive.

\section{Conclusions}

Nitric acid alone cannot liberate $100 \%$ of all REE during digestion of silicate-containing peat and plant matrices. This will also largely explain the discrepancies (mostly too low values) between experimental and certified or indicative values in various plant reference materials determined by ICP-MS after microwave assisted digestion with $\mathrm{HNO}_{3}$ and $\mathrm{H}_{2} \mathrm{O}_{2}{ }^{8}$ The conventional approach, which is to add $\mathrm{HF}$, dissolves siliceous matter reasonably well, but forms insoluble metal fluorides that negatively affect the quantification of REE. The addition of $\mathrm{HBF}_{4}$ to the digestion mixture efficiently solves this problem by simultaneously attacking the silicates while preventing the precipitation of metal fluorides. USN with membrane desolvation provides a high efficiency sample introduction system for ICP-MS which significantly reduces the amount of polyatomic interferences. Oxide formation originating from $\mathrm{Ba}$ and light REE, which hampers the reliable quantification of heavier REE when using conventional pneumatic nebulisation, can thereby be reduced to the point where this problem is negligible.

Based on the experiences gained in this study, the microwave autoclave- $\mathrm{HNO}_{3}-\mathrm{HBF}_{4}$ digestion approach, followed by the quantification of REE with USN-ICP-MS, is recommended for peat and plant material. Studies are now underway to reconstruct the changing rates of atmospheric deposition of REE using peat samples from ombrotrophic bogs, ${ }^{27}$ and to relate these to Holocene climate change.

\section{Acknowledgements}

S. Hann, University of Agriculture, Vienna, Austria, kindly provided the candidate reference material CRM 670 Aquatic Plant. Financial support to M.K. from the Forschungspool of the University of Heidelberg (Project: "Trace element analyses of geological archives: sediments, peat, and ice") is gratefully acknowledged.

\section{References}

1 J. Riondato, F. Vanhaecke, L. Moens and R. Dams, Fresenius' J. Anal. Chem., 2001, 370, 544.

2 T. Prohaska, S. Hann, C. Latkoczy and G. Stingender, J. Anal. At. Spectrom., 1999, 14, 1.

3 J. S. Alvaredo, T. J. Neal, L. L. Smith and M. D. Erickson, Anal. Chim. Acta, 1996, 322, 11.

4 K. Inagaki and H. Haraguchi, Analyst, 2000, 125, 191.

5 X. Cao, G. Zhao, M. Yin and J. Li, Analyst, 1998, 123, 1115.

6 B. Li, Y. Zhang and M. Yin, Analyst, 1997, 122, 543.

7 J. Ivanova, R. Djingova, S. Korhammer and B. Markert, Talanta, 2001, 54, 567.

8 J. Ivanova, S. Korhammer, R. Djingova, H. Heidenreich and B. Markert, Spectrochim. Acta, Part B, 2001, 56, 3.

9 X.-P. Yan, R. Kerrich and M. J. Hendry, J. Anal. At. Spectrom., 1999, 14, 215.

10 A. G. Coedo, M. T. Dorado, I. Padilla and F. J. Alguacil, J. Anal. At. Spectrom., 1998, 13, 1193.

11 L. Halicz, I. Segal and O. Yoffe, J. Anal. At. Spectrom., 1999, 14, 1579 .

12 W. Diegor, H. Longerich, T. Abrajano and I. Horn, Anal. Chim. Acta, 2001, 431, 195.

13 K. Benkhedda, H. Goenaga Infante, E. Ivanova and F. C. Adams, J. Anal. At. Spectrom., 2001, 16, 995.

14 D. Weiss, W. Shotyk, H. Schäfer, U. Loyall, E. Grollimund and M. Gloor, Fresenius' J. Anal. Chem., 1999, 363, 300.

15 M. Krachler, H. Radner and K. J. Irgolic, Fresenius' J. Anal. Chem., 1996, 355, 120.

16 R. Bock, Handbuch der Analytisch-chemischen Aufschlussmethoden, Wiley-VCH, Weinheim, 2001.

17 M. Krachler, W. Shotyk and H. Emons, Anal. Chim. Acta, 2001, 432, 303.

18 M. Krachler, Fresenius' J. Anal. Chem., 2001, 371, 944.

19 Encyclopedia of Geochemistry, ed. C. P. Marshall and R. W. Fairbridge, Kluwer, Dordrecht, 1999.

20 K. J. M. Kramer, W. S. Dorten, H. van het Groenewoud, E. de Haan, G. N. Kramer, L. Monteiro, H. Muntau and $\mathrm{Ph}$. Quevauviller, J. Environ. Monit., 1999, 1, 83.

21 J. Emsley, The Elements, Clarendon Press, Oxford, 3rd edn., 1998.

22 G. Faure, Principles and Applications of Inorganic Geochemistry, MacMillan, New York, 1991.

23 J. J. R. Fraústo da Silva and M. M. Queimado, Rev. Port. Quim., 1973, 15, 29.

24 L. Kolditz and C.-S. Lung, Z. Chem., 1967, 7, 469.

25 E. Anders and M. Ebihara, Geochim. Cosmochim. Acta, 1982, 46, 2363.

26 S. R. Taylor and S. M. McLennan, Rev. Geophys., 1995, 33, 241.

27 W. Shotyk, D. Weiss, J. D. Kramers, R. Frei, A. K. Cheburkin, M. Gloor and S. Reese, Geochim. Cosmochim. Acta, 2001, 65, 2337. 